\title{
COMPLICATIONS OF PLANNED HOME BIRTHS IN THE CZECH REPUBLIC BETWEEN 2016-2017
}

\author{
Petr Křepelka ${ }^{1,2}$, Petr Velebil ${ }^{1,2}$, Alena Měchurováa ${ }^{1,2}$, Zbyněk Straňák ${ }^{1,2}$, Jaroslav Feyereisl ${ }^{1,2}$ \\ ${ }^{1}$ Institute for the Care of Mother and Child, Prague, Czech Republic \\ ${ }^{2}$ Third Faculty of Medicine, Charles University, Prague, Czech Republic
}

\begin{abstract}
SUMMARY
Objective: This study aimed to analyze the complications of planned home births treated at healthcare facilities in the Czech Republic.

Methods: This prospective cohort observational study is based on analysis of women hospitalized with complications related to planned home deliveries in the Czech Republic between 2016 and 2017. The data were collected using an online form made accessible to the directors of all maternity hospitals in the Czech Republic. The results were statistically evaluated.

Results: We identified 45 complications during planned home deliveries. Complications occurred most often among women living in largely populated cities with higher levels of education. Overall, $40 \%$ of patients did not receive routine antenatal care, and $38 \%$ of women gave birth after the 41 st week of pregnancy. In $60 \%$ of cases, no professionals attended the birth. Hospital transfer frequencies were $42 \%$ after delivery, $36 \%$ at third-stage labour, $11 \%$ first-stage labour, $9 \%$ second-stage labour, and $2 \%$ before delivery. We recorded four neonatal deaths and one severe newborn morbidity. There was one maternal death unrelated to the home-birthing process and six cases of severe maternal haemorrhagic shock requiring intensive care.

Conclusion: Complications of planned home births occurred more frequently in women living in largely populated cities and with higher education levels. Planned home births were also observed among women who were at a higher risk of complications. Risk factors included nulliparity, postdate pregnancy, and lack of prenatal care. Hospital transfers occurred most often in the third stage of labour and postpartum.
\end{abstract}

Key words: home birth, complication, neonatal death, maternal morbidity

Address for correspondence: P. Křepelka, Institute for the Care of Mother and Child, Podolské nábřeži 157/36, 14700 Prague, Czech Republic. E-mail: petr.krepelka@upmd.eu

https://doi.org/10.21101/cejph.a5641

\section{INTRODUCTION}

Currently, we face increasing public doubt about the usefulness of obstetric services provided in healthcare facilities, and many are advocating for a return to home birthing. The argument that birth is a natural physiological process with no need for intervention neglects the real risks of childbearing. By the 1970s, the birthing process had moved from homes to healthcare facilities, to limit fatal complications and improve perinatal outcomes. Home births were considered only when healthcare facilities were not available. Systems of facility-based obstetrical care, and the transfer of responsibilities from midwives to obstetricians were followed by a dramatic reduction in maternal and neonatal deaths (1). Thus, planned home birth in developed countries is a relatively new social phenomenon. Preferences for limited interventions, cultural or religious reasons, fear of the hospital environment, freedom of decision-making during childbirth, and request for a home environment are among the most frequent reasons cited by women who opt for home births. Economic or logistical issues related to the accessibility of hospital care are rare (2). Advocates of planned home births point out the evidence for fewer instrumental interventions during delivery (3). Secondary data analyses have documented a lower proportion of vaginal instrumentations during home births; however, no difference in the incidence of emergency Caesarean delivery was reported (4). Planned home births carry a risk of emergency hospital transfer in $9.9-31.9 \%$ of cases (5). This risk is higher among nulliparas (6). Planned home births represent a minority of all births, with one home birth per 49 facility births among Hispanic women, and one home birth per 100 facility births in the overall United States population. About two-thirds of out-of-hospital births are home births (7). In most European countries, home births account for less than $1 \%$ of all births. In England, this rate was 2.5\%, in Wales 3.7\%, in Iceland 1.8\%, and in Scotland 1.4\%. In the Netherlands, where home births are an option for women with uncomplicated pregnancies, $16.3 \%$ of all births occurred at home. This is a substantial change from the 2004 rate, which exceeded $30 \%$, according to the European Perinatal Health Report 2010. Women in the Netherlands now also have the option of giving birth in birth centres (home-like settings) primarily under the care of a midwife. There are 4.3 planned home births for every 1,000 deliveries in France (8). In the Czech Republic, there were 238 out-of-facility births, with 33 births occurring at home according to the Institute of Health Information and Statistics (IHIS) data for 2015. However, it was not possible to distinguish between planned and accidental home births (9). We suppose that in cases of planned home births, the maternal and newborn reports (which are obligatory for healthcare workers present at deliveries or 
performing initial newborn examinations) could be missing, especially when follow-up hospital care was not provided. The data for 2016 and 2017 are not currently available. Results of safety analyses with respect to planned home births are controversial. According to a retrospective study in the Netherlands, home births attended by midwives had the same neonatal mortality as in-hospital births attended by midwives (10). Another cohort study from the Netherlands analyzed 529,688 low-risk women; 60.7\% delivered by planned home births and $30.8 \%$ delivered in a hospital. There were no statistically significant differences in perinatal mortality or serious neonatal morbidity (11). One small Canadian study based on data from 2000-2004 also documented comparable perinatal mortality outcomes for home and hospital births (12). Similarly, a Swedish study from 1992-2004 documented comparable results related to neonatal mortality among home and hospital births; however, the report was based on only 897 planned home births (13). There have been an increasing number of questionable studies documenting greater risks with planned home births compared to hospital births in recent years. A study from the Netherlands that analyzed a cohort of 37,735 low-risk women found an increased risk of perinatal death among those under the primary care of midwives. The risk of perinatal death has been shown to increase when a planned home birth requires an emergency hospital transfer (14). According to a British study, comparable outcomes for planned home births and hospital births have been observed, but only in generally low-risk multiparas with singleton pregnancies. In contrast, home birth risks according to perinatal mortality and serious neonatal morbidity were higher in nulliparas (3). A meta-analysis of 12 studies from developed countries reported that the risk of neonatal death (congenital birth defects excluded) among home births was three times higher than that among hospital births (15). One study from 2013 analyzed the birth outcomes of 14 million low-risk singleton newborns. In that study, the relative risk of low Apgar scores after planned home births was 10-times higher overall and over 14-times higher among nulliparas compared to Apgar scores after hospital births (16). The relative risk of neonatal death is 4 times higher for home births among generally low-risk women, and almost 7 times higher among women having first deliveries and births occurring after the 41 st completed week of gestation (17). Another study from 2015 documented a home-to-hospital transfer rate of $18.8 \%$. Neonatal death and stillbirth risks were higher with planned home births compared to planned hospital births (18). Out-of-facility births, either planned or unplanned, are associated with higher risks of hypoxic-ischaemic encephalopathy of the newborn (19). Public debate about the safety of home births is ongoing. In the literature, a study advocating home births pointed out the State's interference with the rights of midwives to do their jobs (20). The official position of the Czech Gynaecological and Obstetrical Society does not support planned home births because of the real risks of home-based deliveries (21). Opposing views led to a court dispute in front of the European Court of Human Rights (ECHR), in Krejsová against the Czech Republic. The dispute was based on the Czech government's lack of support for planned home births managed by qualified midwives. The Czech Republic postulated the need for technical and medical assistance during labour, which excludes professional attendance in home environments. The ECHR adjudication, however, focused primarily on a solution to human rights legalities - whether a legitimate public interest in protecting newborn health and life outweighs a mother's individual right to privacy. The ECHR accepted arguments that maternal and newborn risks were higher with home births compared to those with hospital births. The Court decided that banning participation of qualified healthcare workers during planned home births interfered with maternal rights to privacy, and that home births without assistance would not interfere with in-home privacy rights (22). Because of limited data on statistical outcomes and complications, a new system of collecting data on home birth complications was started in obstetrical and gynaecological departments in the Czech Republic. This system was created with the support of the Czech Gynaecological and Obstetrical Society. The aim was to collect information on the actual status of home births, specifically related complications, and management methods. These data should provide a basis for further debate on safe birth environments.

\section{MATERIALS AND METHODS}

This was a prospective observational cohort study with data collected from 1 January 2016 to 31 December 2017. Data were provided by chief doctors in all 92 obstetrical and gynaecological departments throughout the Czech Republic by means of an electronic on-line protocol. All department directors obtained individual online access to the database and were informed about the method of data collection. Responsible contacts were designated at each facility to maintain contact with the researchers from the Institute for the Care of Mother and Child in Prague, and to allow validation of the entered data. Study enrolment criteria included: any identified planned home births culminating in transfers to hospital obstetrical units during labour, or within six weeks after delivery, due to suspected or diagnosed complications of labour, or suspected/diagnosed pathology in the mother and/or newborn related to birth.

The dataset consisted of the following variables: maternal age, level of education, gravidity, parity, gestational age, course of prenatal care (according to the national standards defined by the Section of Perinatology and Foetomaternal Medicine of the Czech Gynaecological and Obstetrical Society), willingness to cooperate with healthcare workers, the attending provider at home, the reason for hospital transfer, mode of delivery, the status of the patient, necessary treatment measures and resulting outcomes, and the size of the place of residence by the population. Variables related to newborns included: birthweight, status after delivery, necessary treatment measures, and resulting outcomes. For numerical variables, the mean, median, and interquartile range were determined. Categorized variables were expressed using absolute frequency and percentage. The statistical descriptive analysis was conducted using SPSS Statistics 19 (SPSS Inc, Chicago, Illinois, USA) software. This study was approved by the Ethics Committee of the Institute for the Care of Mother and Child in Prague.

\section{RESULTS}

Our study set comprised 45 patients with complications after planned home births that were subsequently treated in the 
hospital's maternity ward. The median age of the women with complications was 33 years (IQR 9.5), the median gestational age of pregnancy was 40 weeks (IQR 2), and the median newborn birthweight was $3,180 \mathrm{~g}$ (IQR 740) (Table 1). There were 22 (48.9\%) nulliparae, 17 (37.8\%) primiparae, 4 (8.9\%) secundiparae, and $2(4.4 \%)$ tertiparae or more (Table 2$).$

Regarding education levels, as shown in Table 2, there were $2(4.4 \%)$ women with basic education and 19 (42.2\%) women with university educations. Regarding the population size of residence, $22(48.9 \%)$ of the patients resided in cities with more than 90,000 inhabitants. Twenty-four women $(53.3 \%)$ received standard prenatal care from an obstetrician during their pregnancies, $7(15.6 \%)$ had no prenatal care. According to the healthcare workers who treated women with complications, $8(17.8 \%)$ of the women showed no willingness to cooperate with the medical staff and $16(35.6 \%)$ were sufficiently willing to cooperate. Regarding professional staff in attendance at the births, $2(4.4 \%)$ births were attended by physicians, 16 (35.6\%) by midwives, $6(13.3 \%)$ by a partner, in $11(24.4 \%)$ cases by another lay person, and in $10(22.2 \%)$ cases the attendant's status was not identified (Table 2). Table 2 also shows the information on the numbers of hospital transfers in each stage of labour and delivery. A hospital transfer was required most often after birth - in 19 cases $(42.2 \%)$. In $1(2.2 \%)$ case, the reason for the transfer before delivery was foetal death. The indications for hospital transfer among patient undergoing planned home births is shown in Table 3. Altogether, there were 41 (91.1\%) spontaneous vaginal deliveries, and Caesarean sections were required in 4 (8.9\%) cases (Table 2). Asphyxia was diagnosed in $1(2.2 \%)$ newborn, asphyxia and hypothermia were diagnosed in $2(4.4 \%)$, newborn hypothermia was diagnosed in 3 $(6.7 \%)$, and newborn status was described as physiological in $33(73.3 \%)$ (Table 4$)$. There were $4(8.9 \%)$ perinatal deaths and in $2(4.4 \%)$ newborns, the condition was unknown. Intensive care was required for $6(13.0 \%)$ of the newborns, $3(7.0 \%)$ required resuscitation, $1(2.0 \%)$ required controlled hypothermia, and $35(78.0 \%)$ required no specialized neonatal care. The condition of the newborns was physiological in $36(80.0 \%)$, temporary morbidities were reported in $4(8.9 \%), 1(2.2 \%)$ newborn had permanent morbidity, and there were $4(8.9 \%)$ perinatal deaths. The maternal conditions during the transfers were described as physiological in $38(84.4 \%)$ patients. In 2 $(4.4 \%)$ cases, the parturients required intensive care unit admissions, $8(17.8 \%)$ required surgical treatments, $6(13.3 \%)$ required blood derivative administration. Twenty-nine (64.4\%) of the patients did not require any specialized obstetric care. Temporary morbidities were present in $3(6.7 \%)$ patients, but $41(91.1 \%)$ were assessed as physiologically normal. There was $1(2.2 \%)$ maternal death (Table 4$)$.

\section{DISCUSSION}

Our study describes 45 cases of planned home birth complications that required medical management during labour or the postpartum period in obstetrical and gynaecological departments in the Czech Republic between 1 January 2016 and 31 December 2017. This study is relevant because, to the best of our knowledge, it is the first documented attempt to analyze home birth complications on a nationwide scale. Official data on this issue are not available and have not yet been systematically analyzed. Based on the data collected, we grossly estimated the total number of planned home births. The proportion of necessary transfers has been reported as $10-32 \%$, indicating that the number of planned home births would be approximately $140-250$ per year (5). This would represent approximately $0.14-0.25 \%$ of all births in the Czech Republic, confirming the assumption that planned home births account for a very small proportion of births in the Czech Republic. This study described the basic demographic data of women who experienced planned home birth complications. The mean age of the women was 33 years, which is higher than the national average. Approximately $50 \%$ of the women were residents in cities with over 90,000 inhabitants, with most residing in Prague. Many women had university or high school education. The basic characteristics of women with home birth complications were as follows: older-than-average ages, residents of large cities, and higher levels of education. Demographic factors suggest that the choice of a home birth occurs more frequently in women of older-than-average age who live in larger cities, especially in the capital, and have higher levels of education; however, we did not identify specific fields of the study. We may suppose that women opting for home birth have had sufficient education to enhance their judgement about the risks of labour. Our data on the frequency of choosing home births among women with university education are consistent with published data showing that this option is chosen more frequently by married, university-educated Caucasian women (23). Additionally, women who opted for home births had factors that increased their home birth risks. Almost half of the women in our study were nulliparous, and $38 \%$ of them delivered after the completed 41 st week of gestation (41+ 0 or later). Nulliparity, delivery at $41+0$ weeks or later, history of prior Caesarean delivery, multiple gestation, and non-vertex foetal position are factors that substantially increased the risks during planned home births and are contraindications to births outside hospital. Overall, the neonatal death risk with planned home births was $12.6 / 10,000$ births compared to $3.2 / 10,000$ births attended by midwives in a hospital setting, and 5.09/10,000 births attended by physicians in a hospital setting. Neonatal mortality increased to $18.4 / 10,000$ births and 21.9/10,000 births when nulliparity and delivery $\geq 41$ weeks of gestation, respectively, were

Table 1. Numerical variables of women at delivery and newborns $(N=45)$

\begin{tabular}{|l|c|c|c|c|c|c|c|}
\hline Study population & Mean & Median & Min & Max & Q1 & Q3 & IQR \\
\hline Age (years) & 32.6 & 33 & 21 & 42 & 28 & 37.5 & 9.5 \\
\hline Gestational age (weeks) & 40 & 40 & 34 & 44 & 39 & 41 & 2 \\
\hline Birthweight (g) & 3,216 & 3,180 & 1,640 & 4,520 & 2,940 & 3,600 & 740 \\
\hline
\end{tabular}

IQR - interquartile range 
Table 2. Characteristics of women at delivery and circumstances of transfer to hospital $(N=45)$

\begin{tabular}{|c|c|c|}
\hline & $\mathrm{n}$ & $\%$ \\
\hline \multicolumn{3}{|l|}{ Age (years) } \\
\hline$\leq 24$ & 6 & 13.3 \\
\hline $25-29$ & 11 & 24.4 \\
\hline $30-34$ & 8 & 17.8 \\
\hline $35-39$ & 15 & 33.3 \\
\hline$\geq 40$ & 5 & 11.1 \\
\hline \multicolumn{3}{|l|}{ Gravidity } \\
\hline 1 & 15 & 33.3 \\
\hline 2 & 18 & 40.0 \\
\hline 3 & 6 & 13.3 \\
\hline$\geq 4$ & 6 & 13.3 \\
\hline \multicolumn{3}{|l|}{ Parity } \\
\hline 0 & 22 & 48.9 \\
\hline 1 & 17 & 37.8 \\
\hline 2 & 4 & 8.9 \\
\hline$\geq 3$ & 2 & 4.4 \\
\hline \multicolumn{3}{|l|}{ Gestational age (weeks) } \\
\hline$\leq 37$ & 4 & 8.9 \\
\hline $38-40$ & 24 & 53.3 \\
\hline $41-42$ & 12 & 26.7 \\
\hline$\geq 43$ & 5 & 11.1 \\
\hline \multicolumn{3}{|l|}{ Education } \\
\hline Basic & 2 & 4.4 \\
\hline High school & 8 & 17.8 \\
\hline Secondary with GCSE & 16 & 35.6 \\
\hline University & 19 & 42.2 \\
\hline \multicolumn{3}{|l|}{ Residence } \\
\hline City up to 3,000 inhabitants & 8 & 17.8 \\
\hline City of $3,000-6,000$ inhabitants & 3 & 6.7 \\
\hline City of $6,000-11,000$ inhabitants & 5 & 11.1 \\
\hline City of $11,000-25,000$ inhabitants & 2 & 4.4 \\
\hline City of $25,000-47,500$ inhabitants & 2 & 4.4 \\
\hline City of $47,500-90,000$ inhabitants & 3 & 6.7 \\
\hline City over 90,000 inhabitants & 22 & 48.9 \\
\hline \multicolumn{3}{|l|}{ Prenatal care } \\
\hline Standard prenatal care from an obstetrician & 24 & 53.3 \\
\hline Non-standard prenatal care & 11 & 24.4 \\
\hline Absence of prenatal care & 7 & 15.6 \\
\hline Not identified & 3 & 6.7 \\
\hline \multicolumn{3}{|c|}{ Willingness of the woman to cooperate during labour } \\
\hline None & 8 & 17.8 \\
\hline Limited & 21 & 46.7 \\
\hline Sufficient & 16 & 35.6 \\
\hline \multicolumn{3}{|l|}{ Person assisting with childbirth } \\
\hline Doctor & 2 & 4.4 \\
\hline Midwife & 16 & 35.6 \\
\hline
\end{tabular}

\begin{tabular}{|c|c|c|}
\hline & $\mathrm{n}$ & $\%$ \\
\hline Partner & 6 & 13.3 \\
\hline Another lay person & 11 & 24.4 \\
\hline Not identified & 10 & 22.2 \\
\hline \multicolumn{3}{|c|}{ Circumstances of hospital transfer } \\
\hline Before birth & 1 & 2.2 \\
\hline 1st stage of labour & 5 & 11.1 \\
\hline 2nd stage of labour & 4 & 8.9 \\
\hline 3rd stage of labour & 16 & 35.6 \\
\hline After birth & 19 & 42.2 \\
\hline \multicolumn{3}{|l|}{ Modality of delivery } \\
\hline Vaginal delivery & 41 & 91.1 \\
\hline Caesarean section & 4 & 8.9 \\
\hline
\end{tabular}

factors (17). According to a previous study, neonatal death risks with planned home births include nulliparity (odds ratio (OR) 2.71, 95\% confidence interval (CI) 1.71-4.31), previous Caesarean section (OR 2.62, 95\% CI 1.25-5.52), non-vertex foetal position (OR 4.27, 95\% CI 1.33-13.75), multiple gestation (OR 9.79, 95\% CI 4.25-22.57), preterm birth (OR 4.68, $95 \%$ CI $2.30-9.51)$, and delivery at $\geq 41$ weeks of gestation (OR 1.76, 95\% CI 1.09-2.84). Delivery after 40 completed weeks increases the risk of perinatal death, foetal asphyxia, foetal distress during labour, neonatal sepsis, meconium aspiration syndrome, and neonatal intensive care unit (NICU) admission. These risks are further increased in women $\geq 35$ years old and women with body mass index $>35 \mathrm{~kg} / \mathrm{m}^{2}$ (24). Recommendations against planned home births among women with these risk factors may contribute to a reduction in neonatal

Table 3. Indications for transfer to hospital $(N=45)$

\begin{tabular}{|c|c|c|}
\hline & $\mathrm{n}$ & $\%$ \\
\hline \multicolumn{3}{|l|}{ Transfer before delivery } \\
\hline Foetal death & 1 & 2.2 \\
\hline \multicolumn{3}{|l|}{ First stage of labour } \\
\hline Protracted stage 1 & 3 & 6.4 \\
\hline Bleeding & 1 & 2.2 \\
\hline Foetal hypoxia & 1 & 2.2 \\
\hline \multicolumn{3}{|l|}{ Second stage of labour } \\
\hline Arrested labour & 3 & 6.4 \\
\hline Malposition of the foetus & 1 & 2.2 \\
\hline \multicolumn{3}{|l|}{ Third stage of labour } \\
\hline Retained placenta & 6 & 13.3 \\
\hline Bleeding & 4 & 8.9 \\
\hline Status of the newborn & 1 & 2.2 \\
\hline \multicolumn{3}{|l|}{ Transfer after delivery } \\
\hline Birth injury & 4 & 8.9 \\
\hline Bleeding & 6 & 13.3 \\
\hline Status of the newborn & 9 & 20.0 \\
\hline
\end{tabular}


Table 4. Indicated care and health outcomes of newborns and mothers $(N=45)$

\begin{tabular}{|c|c|c|}
\hline & $\mathrm{n}$ & $\%$ \\
\hline \multicolumn{3}{|l|}{ Status of the newborn } \\
\hline Asphyxia & 1 & 2.2 \\
\hline Asphyxia + hypothermia & 2 & 4.4 \\
\hline Normal & 33 & 73.3 \\
\hline Hypothermia & 3 & 6.7 \\
\hline Death & 4 & 8.9 \\
\hline Not identified & 2 & 4.4 \\
\hline \multicolumn{3}{|l|}{ Care of the newborn } \\
\hline Intensive care & 6 & 13.0 \\
\hline Resuscitation & 3 & 7.0 \\
\hline Controlled hypothermia & 1 & 2.0 \\
\hline None & 35 & 78.0 \\
\hline \multicolumn{3}{|l|}{ Resulting condition of the newborn } \\
\hline Temporary morbidity & 4 & 8.9 \\
\hline Physiological & 36 & 80.0 \\
\hline Permanent morbidity & 1 & 2.2 \\
\hline Perinatal death & 4 & 8.9 \\
\hline \multicolumn{3}{|l|}{ Status of the parturient during transfer } \\
\hline Physiological & 38 & 84.4 \\
\hline Haemorrhagic shock & 6 & 13.3 \\
\hline Other shock & 1 & 2.2 \\
\hline \multicolumn{3}{|l|}{ Care of the parturient } \\
\hline Intensive care & 2 & 4.4 \\
\hline Surgical care & 8 & 17.8 \\
\hline Administration of blood products & 6 & 13.3 \\
\hline None & 29 & 64.4 \\
\hline \multicolumn{3}{|l|}{ Resulting condition of the parturient } \\
\hline Temporary morbidity & 3 & 6.7 \\
\hline Physiological & 41 & 91.1 \\
\hline Death & 1 & 2.2 \\
\hline
\end{tabular}

mortality during planned home births (25). In our study, 44\% of women were $\geq 35$ years old. The combination of $\geq 35$ years of age, nulliparity, and gestational age $\geq 41$ weeks occurred three times during the 2-year study period, and two of these combinations resulted in neonatal deaths. These facts might reflect unfamiliarity with or naivety towards known risk factors among the women considering a planned home birth. The majority of hospital transfers resulted from complications in the 3rd stage of labour or after delivery. Twenty percent of women were transferred during stages 1 and 2 of labour, and $78 \%$ were transferred in stage 3 or after delivery.

\section{Transfer Before Labour}

We identified one patient who sought hospital care before the onset of labour. She repeatedly refused induction of labour after her 41 st week, and despite being informed of the increased risk of stillbirth by her obstetrician, she desired home birth and awaited spontaneous labour. She obtained a foetal heartbeat monitor and measured foetal heart tones on her own. She contacted the hospital only after the foetal heartbeat had disappeared. She consented to induction of labour of the dead foetus in the 44th week of gestation. The induction was unsuccessful, and Caesarean section was performed to deliver the dead foetus weighing 4,520 grams.

\section{Transfers in the First and Second Stages of Labour}

We registered three cases of arrest disorders in the 1st stage of labour. After hospital transfer and further augmentation of uterine activity using oxytocin, uncomplicated deliveries occurred. Another three patients with arrest disorders in the 2nd stage of labour underwent uncomplicated Caesarean sections with good maternal and newborn outcomes. Arrested labour is a frequent complication and is the most frequent reason for hospital transfer during planned home births, in $5.1-9.8 \%$ of cases $(6,26)$. Intrauterine foetal distress was the reported reason for transfer in only one case in our study. However, two cases of foetal distress resulted in intrapartum deaths. One of the newborns, born at home with signs of severe asphyxia, died despite resuscitation by the rapid emergency team called to the scene. These cases provide evidence of the complications that can occur with ineffective or absence of foetal well-being monitoring during home births. Foetal distress during labour is reported to be a reason for transfer from home to the hospital in $1-3.6 \%$ of cases (5).

\section{Transfers in the Third Stage of Labour}

In our study, retained placenta was the cause of six hospital transfers in the 3rd stage of labour, which was noteworthy. Retained placenta occurs in approximately $0.1-3.3 \%$ of all births (27). Cases of placental adherence were managed by manual extraction of the placenta without further complications. In four cases, the reason for hospital transfer was obstetrical haemorrhage in the 3 rd stage of labour. In one case, the reason for transfer was neonatal asphyxia in the 3rd stage.

\section{Postpartum Hospital Transfer}

Transfers after delivery were mostly performed because of postpartum bleeding. Of 6 cases of haemorrhage in total, 4 were classified as precursors of haemorrhagic shock. Haemorrhagic shock is considered an emergency because it poses an immediate threat to life of the mother. In our study, all cases of haemorrhagic shock were treated and resolved using anti-shock measures and blood derivative administration. Postpartum bleeding is reported in the literature to be a rare indication for transfer, occurring in only $0.2 \%$ of cases (5). Vaginal and perineal injuries were reasons for standard in-hospital repairs in four cases, and there were no serious complications. Perineal labour injuries occur in $77-86 \%$ of deliveries, but only $60 \%$ of them require repair (28). Labour injuries to the vagina and perineum are reported to occur less frequently with planned home births (29). The most frequent reason for transfer of the mother and newborn after delivery was the status of the newborn. Transfers due to newborn respiratory complications after delivery are reported to occur in $0.3-1.4 \%$ 
of planned home births (5). Of 10 endangered newborns in our study, 6 required intensive neonatal care, and 3 of those required cardiopulmonary resuscitation. In one case, controlled hypothermia had to be used. With respect to neonatal outcomes, three patients had temporary neonatal morbidities, which resulted in permanent damage in one. In our dataset we had two intrapartum deaths due to hypoxia during labour and one asphyxiated newborn who died immediately after birth. Intrapartum hypoxia was the most important factor related to perinatal mortality and morbidity in our study. This finding agrees with published data, showing that the contribution of intrauterine hypoxia to neonatal mortality in planned home births was up to $52 \%$ (30). Neonatal deaths after home births occur more frequently compared to those after hospital births. In the Czech Republic, perinatal mortality is very low in the long term and is around five cases per 1,000 live births, which is almost ten times less than in our dataset (9). However, maternal deaths during planned home births are the exception in developed countries. The greatest risk for maternal death is labour with no professional help. In our study, we had one maternal death after a planned home birth due to a thromboembolic event in the puerperium that was unrelated to the home birth process. Another important finding that showed the increased risk of planned home births in our study was the fact that $60 \%$ of births were attended by a partner, another lay person, or a person without further classification. This is probably related to current legal regulations in the Czech Republic, which specify that the material and technical requirements for labour assistance cannot be met in home environments. Assisting midwives sometimes deny that they intended to be present for planned home births, reporting their presence as "happenstance" during supposedly acute, "unplanned" home birth situations. This overall situation has also been illustrated by the limited or absence of willingness of expectant women to cooperate with care workers in hospital perinatal care. The lack of professional assistance in planned home births creates a strong demand for early identification of complications and indications for emergency hospital transfers.

Our study has several limitations. The data collection was based on a voluntary sharing of data by informed workers in all hospital obstetrical departments. It is quite probable that the true number of complications was underreported. Moreover, cases that occurred during the study period and are under legal dispute were not included nor published. Another limitation is the small size of our cohort, which also reflects the fact that there are not a large number of planned home births in the Czech Republic. To the best of our knowledge, our study is novel and may potentially be further developed and mapped to show relationships between places of birth and specific related risks. Our findings should stimulate professional debates on ethics and professional integrity related to the clinical practice and available scientific evidence of the safety of planned home births.

\section{CONCLUSIONS}

Planned home births represent only a small segment of healthcare issues in the Czech Republic; however, they are linked to serious maternal and neonatal morbidity and mortality. Planned home birth complications occurred more often in larger cities, among women with higher education levels, and compared to the national average, in women of older ages. Complications occurred in women with one or more risk factors, including nulliparity, birth after the 41 st week of gestation, maternal age 40 years and older, lack of prenatal care, and lack of professional assistance during labour. There were 4 perinatal deaths, all in women with risk factors for planned home births. This study provides a basis for further public debate regarding the birthing environment and its safety for both mothers and newborns in the Czech Republic. It provides a good perspective for further analyses in this field of medicine. Future studies with larger study populations are needed to verify these results and potentially improve the existing practices.

\section{Conflict of Interests}

None declared

\section{REFERENCES}

1. Loudon I. The transformation of maternal mortality. BMJ. 1992;305(6868):1557-60.

2. Lindgren HE, Rådestad IJ, Christensson K, Wally-Bystrom K, Hildingsson IM. Perceptions of risk and risk management among 735 women who opted for a home birth. Midwifery. 2010;26(2):163-72.

3. Birthplace in England Collaborative Group, Brocklehurst P, Hardy P, Hollowell J, Linsell L, Macfarlane A, McCourt C, et al. Perinatal and maternal outcomes by planned place of birth for healthy women with low risk pregnancies: the Birthplace in England national prospective cohort study. BMJ. 2011 Nov 23;343:d7400. doi: 10.1136/bmj.d7400.

4. Hollowell J, Li Y, Bunch K, Brocklehurst P. A comparison of intrapartum interventions and adverse outcomes by parity in planned freestanding midwifery unit and alongside midwifery unit births: secondary analysis of 'low risk' births in the birthplace in England cohort. BMC Pregnancy Childbirth. 2017; 17:95. doi: 10.1186/s12884-017-1271-2.

5. Blix E, Kumle M, Kjærgaard H, Oian P, Lindgren HE. Transfer to hospital in planned home births: a systematic review. BMC Pregnancy Childbirth. 2014;14:179. doi:10.1186/1471-2393-14-179.

6. Lindgren HE, Radestad IJ, Hildingsson IM. Transfer in planned home births in Sweden - effects on the experience of birth: a nationwide population-based study. Sex Reprod Healthc. 2011;2(3):101-5.

7. Dunham B. Home birth midwifery in the United States. Hum Nat. 2016;27(4):471-88.

8. Zeitlin J, Mohangoo A, Delnorn M, editors. European perinatal health report. The health and care of pregnant women and babies in Europe in 2010. Paris: Euro Peristat; 2013.

9. Institute of Health Information and Statistics of the Czech Republic. Mother and newborn 2014-2015 [Internet]. Prague: IHIS CR; 2017 [cited 2018 0ct 10]. Available from: https://www.uzis.cz/sites/default/ files/knihovna/rodnov2014_2015.pdf. (In Czech, English.)

10. van der Kooy J, Poeran J, de Graaf JP, Bimie E, Denktass S, Steegers EA, et al. Planned home compared with planned hospital births in the Netherlands: intrapartum and early neonatal death in low-risk pregnancies. Obstet Gynecol. 2011;118(5):1037-46.

11. de Jonge A, van der Goes BY, Ravelli AC, Amelink-Verburg MP, Mol BW, Nijhuis JG, et al. Perinatal mortality and morbidity in a nationwide cohort of 529,688 low-risk planned home and hospital births. BJOG. 2009;116(9):1177-84.

12. Janssen PA, Saxell L, Page LA, Klein MC, Liston RM, Lee SK. Outcomes of planned home birth with registered midwife versus planned hospital birth with midwife or physician. CMAJ. 2009;181(6-7):377-83.

13. Lindgren HE, Radestad IJ, Christensson K, Hildingsson IM. Outcome of planned home births compared to hospital births in Sweden between 1992 and 2004. A population-based register study. Acta Obstet Gynecol Scand. 2008;87(7):751-9.

14. Evers AC, Brouwers HA, Hukkelhoven CW, Nikkels PG, Boon J, van Egmond-Linden A, et al. Perinatal mortality and severe morbidity in low and high risk term pregnancies in the Netherlands: prospective cohort study. BMJ. 2010 Nov 2;341:c5639. doi: 10.1136/bmj.c5639.

15. Wax JR, Lucas FL, Lamont M, Pinette MG, Carlin A, Blackstone J. Maternal and newborn outcomes in planned home birth vs planned hospital 
births: a metaanalysis. Am J Obstet Gynecol. 2010 Sep;203(3):243.e1-8. doi: 10.1016/j.ajog.2010.05.028.

16. Grunebaum A, McCullough LB, Sapra KJ, Brent RL, Levene MI, Arabin $\mathrm{B}$, et al. Apgar score of 0 at 5 minutes and neonatal seizures or serious neurologic dysfunction in relation to birth setting. Am J Obstet Gynecol. 2013 Oct;209(4):323e1-6. doi: 10.1016/j.ajog.2013.06.025.

17. Grunebaum A, McCullough LB, Sapra KJ, Brent RL, Levene MI, Arabin $\mathrm{B}$, et al. Early and total neonatal mortality in relation to birth setting in the United States, 2006-2009. Am J Obstet Gynecol. 2014;211(4):390. e1-7. doi: 10.1016/j.ajog.2014.03.047.

18. Snowden JM, Tilden EL, Snyder J, Quigley B. Planned out-of-hospital birth and birth outcomes. N Engl J Med. 2015;373(27):2642-53.

19. Wasden SW, Chasen ST, Perlman JM, Illuzze JL, Chervenak FA, Grunebaum A, et al. Planned home birth and the association with neonatal hypoxic ischemic encephalopathy. J Perinat Med. 2017;45(9):1055-60.

20. Königsmarková I. Homebirth in Czech Republic. Ceska Gynekol. 2012;77(6):558-62. (In Czech.)

21. Krrepelka $P$, Velebil $P$. The safety of home birth and evidence-based medicine. Ceska Gynekol. 2012;77(6):555-8. (In Czech.)

22. Chervenak FA, Grünebaum A, Arabin B, McCullough LB. The European Court of Human Rights on planned home birth: resolution of a paradoxical ruling. BJOG. 2017;124(10):1472-3.

23. Boucher D, Bennett C, McFarlin B, Freeze R. Staying home to give birth: why women in the United States choose home birth. J Midwifery Womens Health. 2009;54(2):119-26.

24. Bachilova S, Czuzoj-Shulman N, Abenhaim HA. Effect of maternal and pregnancy risk factors on early neonatal death in 41004 planned home births delivering at home. J Obstet Gynaecol Can. 2018;40(5):540-6.
25. Zizzo AR, Kirkegaard I, Pinborg A, Ulbjerg N. Decline in stillbirths and perinatal mortality after implementation of a more aggressive induction policy in post-date pregnancies: a nationwide register study. Acta Obstet Gynecol Scand. 2017;96(17):862-7.

26. Cox KJ, Bovbjerg ML, Cheyney M, Leeman LM. Planned Home VBAC in the United States, 2004-2009: outcomes, maternity care practices, and implications for shared decision making. Birth. 2015;42(4):299-308.

27. Maher MA, Sayyed TM, Elkhouly NI. Different routes and forms of uterotonics for treatment of retained placenta: a randomized clinical trial. J Matern Fetal Neonatal Med. 2017;30(18):2179-84.

28. Albers LL, Sedler KD, Bedrick EJ, Teaf D, Peralta P. Midwifery care measures in the second stage of labor and reduction of genital tract trauma at birth: a randomized trial. J Midwifery Womens Health. 2005;50(5):36572.

29. Edqvist M, Blix E, Hegaard HK, Ólafsdottir OÁ, Hildingsson I, Ingversen K, et al. Perineal injuries and birth positions among 2992 women with a low risk pregnancy who opted for a homebirth. BMC Pregnancy Childbirth. 2016;16:196. doi 10.1186/s12884-016-0990-0.

30. Bastian H, Keirse MJ, Lancaster PA. Perinatal death associated with planned home birth in Australia: population based study. BMJ. 1998 Aug 8;317(7155):384-8.

Received December 13, 2019

Accepted in revised form July 14, 2020 